\title{
CONSIDERAÇÕES SOBRE O CORPO MUSICAL
}

\author{
Barbara Biscaro \\ Doutora pelo Programa de Pós-Graduação em Teatro da Universidade do Estado de Santa Catarina \\ Email: barbara.biscaro@gmail.com
}

Resumo

Neste artigo teço reflexões sobre o corpo musical, partindo das teorias do Gesto Musical. Para compreender o que seria um corpo musical, abordo conceitos das ciências cognitivas e do estudo do movimento, com o objetivo de problematizar as visões de corpo na música. A metáfora do corpo como instrumento é posta em discussão, a partir do momento que os estudos em Gesto Musical reivindicam diferentes formas de vivenciar/olhar para o corpo na experiência musical/sonora. Elementos como a Estética da Sonoridade e as intersecções entre música e teatro complementam uma discussão, acerca da intersecção entre as artes na performance cênica.

Palavras-chave

Corpo. Gesto. Música. Teatro Keywords

Body. Gesture. Music. Theatre

Abstract

This article contains reflections about the musical body, starting from the theories of Musical Gesture. To understand what would be a musical body, cognitive science concepts and approach of the study of movement are used, with the aim of discussing different visions of body in music. The metaphor of the body as an instrument is put under discussion, from the moment that the Musical Gesture studies claim various forms of experience/look at the body in the music/sound experience. Elements such as the aesthetics of Sound and the intersections between music and drama complement a discussion about the intersection between the arts in scenic performance. 
Minha pesquisa se concentra em problematizar e refletir sobre as possíveis intersecções entre as áreas do Teatro e da Música. Dentre muitos cruzamentos entre os dois campos, meu interesse reside não em gêneros já consolidados a partir da junção destas duas áreas como a Ópera ou o Teatro Musical - e nem em aspectos funcionais em que uma área pretende 'ajudar' a outra: por exemplo, neste artigo não vou me ater a aspectos como as possíveis contribuições que um treinamento em técnicas de dança ou atuação podem dar a um músico em sua postura cênica no momento da performance musical, ou refletir sobre as possibilidades que um treinamento musical dado a um ator - como tocar um instrumento, aprender a cantar - podem criar em termos de aumento de suas habilidades cênicas. O meu interesse está em uma pesquisa que procure territórios que não partam da subordinação de uma só área: sem predominância de uma sobre outra, um artista inserido nesse contexto seria aquele que não vê separação ou hierarquia entre fazer música e fazer teatro, mas sim percebe os dois campos como ações sobrepostas que criam uma lógica própria, um projeto de mundo.

Roland Barthes, em seu livro Aula, escreve que pesquisar é ensinar aquilo que não se sabe. Li esse texto há muitos anos e essa possibilidade sempre permaneceu em minha cabeça: pesquisar pode ser também buscar aquilo que não se sabe, pode ser procurar em vestígios ou intuições alguns fios da meada que podem ser puxados para constituírem campos de pesquisa.

Quando entrei em contato com os estudos do Gesto Musical - ou da música como gesto -encontrei alguns fios da meada para pensar possíveis entrecruzamentos entre os campos da música e do teatro que, para mim, consti- tuem um território híbrido; o centro dessa intersecção está no corpo em performance (seja a performance musical ou cênica) e, pensar elementos como corpo, gesto e movimento são os pontos de partida para compreender como os estudos em Gesto Musical podem contribuir para uma compreensão 'encarnada' da experiência da performance.

Anthony Gritten e Elaine King, pesquisadores em música que organizaram o livro Music and Gesture (2006), escrevem que este é um campo de pesquisa que vem atraindo cada vez mais pesquisadores da área da Música. Precursores na área, como Robert Hatten (2004), abriram caminho para pensar um campo de pesquisa capaz de gerar um

Movimento que se distancia de mode-
los limitados das orientações musico-
lógicas pressupostas sobre o conceito
do trabalho e sua textualidade em di-
reção a modelos mais amplos, orien-
tados ao redor e no interior da realiza-
ção performática e da performance (e,
recentemente, gravação): movimento
que se distancia de uma visão limitada
sobre o corpo musical ${ }^{1}$ (Gritten, King,
2006, p. XIX, tradução nossa).

Esse movimento em direção à performance, partindo dos estudos do corpo, pode envolver diversos pontos de vista: criação/composição, pesquisas em sonoridade, aspectos físicos que envolvem as técnicas de instrumento e aspectos da recepção são alguns dos possíveis caminhos para abordar esse corpo musical. Essa diversidade de pontos de vista, também ressaltada por Gritten e King, ao invés de enfraquecer o campo de pesquisa, evidencia que

1 Movement away from narrow models of musicological engagement predicated upon the work concept and its textuality towards broader models geared around and within performing and performance (and, recently, recording): movement away from a narrow focus on the musical mind towards broader focus on the musical body (Gritten, King, 2006, p. XIX). 
a busca pela conceituação/prática do Gesto Musical é uma proposta de alargamento de perspectivas no pensamento musical. Assim como frisa o excerto acima, a proposta é uma diversificação das possibilidades de pensar, conceituar, analisar e vivenciar música, partindo de diferentes proposições que levam em alta consideração o corpo.

Porém se faz necessário, primeiramente, estabelecer um critério para falar sobre o corpo em performance. Uma abordagem bastante difundida do corpo nos estudos musicais estabelece a metáfora do corpo como instrumento ou do corpo como máquina; é bastante comum, por exemplo, encontrar manuais de estudo de instrumentos musicais (no contexto da música ocidental) que sistematizam exercícios que estimulam habilidades mecânicas do movimento do corpo em prol de um 'domínio' do instrumento; o domínio do instrumento acarreta uma idéia bastante clara de domínio do corpo. Frequentemente, a voz é adjetivada como um instrumento, o quê cria uma espécie de esquizofrenia, nesse caso, pois pressupõe o domínio mecânico de algo que está dentro do próprio corpo do cantor, para seu uso. Portanto, em música (e também em teatro, muitas vezes), expressões como uso do corpo, domínio do corpo e mecanização de movimentos do corpo são comuns no cotidiano de aprendizado de instrumentistas e cantores.

Os pesquisadores George Lakoff e Mark Johnson elaboraram a teoria das metáforas do corpo, no campo das ciências cognitivas. Seu livro, Philosofy in the Flesh (1999), lançou as bases para um pensamento da chamada embodiedmind, ou mente encarnada, pontuando que as metáforas através das quais conceituamos o corpo são muito mais do que pensamentos teóricos: as metáforas são uma forma de conformação dos corpos, das sensações e das subjetividades dos seres humanos, ou seja, "mais do que presentes no discurso verbal ou escrito, as metáforas estão incrustadas nas formas de ação e sustentam o comportamento humano em geral" (Nunes, 2009, p. 45). A partir das teorias de Lakof e Johnson, a pesquisadora Sandra Meyer Nunes, em seu livro As Metáforas do Corpo em Cena (2009), traçou um panorama filosófico das visões do corpo em cena em diferentes períodos históricos da cultura ocidental, ressaltando que "a metáfora do instrumento conforma a ideia de que alguém ou algo de fora manipula e coordena as atividades de dentro. [...] A metáfora do instrumento condena o corpo a ser instrumento de algo fora dele, ao invés de agente de seu próprio processo" (Nunes, 2009, p. 45). Ou seja, usar ou dominar o corpo parte do pressuposto de uma cisão: há o indivíduo e há o corpo a ser manipulado. O que é importante notar é que o aprendizado de um instrumento costuma ultrapassar essas barreiras mecanicistas e instrumentais: instrumento e musicista frequentemente são descritos (na prática) como uma amálgama, uma extensão de um no outro, estabelecendo uma relação muito mais complexa do que uma simples noção de domínio ou de uso. Porém as bases conceituais e filosóficas em prol de uma abordagem mais complexa da experiência do corpo em música ainda estão fortemente influenciadas pela metáfora do corpo como instrumento.

É evidente que essa abordagem do corpo criou e continua criando resultados eficazes. Mas cria também, corpos específicos, com subjetividades específicas e até mesmo musicalidades específicas. Em minha opinião, uma mudança no modo de conceituar a experiência do corpo em música não tem como 
objetivo suplantar a visão instrumental, negando sua eficácia; mas tem como objetivo frisar que existem outras possibilidades de vivenciar o corpo musical (inclusive negando a própria ideia de eficácia em arte). A superação de uma visão instrumental, em minha opinião, é um dos modos de criar uma consciência mais abrangente em cantores (que constituem principalmente a área de meus estudos) de sua corporeidade como projeto existencial: cantar, muito além de uma ação mecânica, muito além de um modo de usar o próprio corpo para 'fazer música', é um projeto de vida, um modo de construção e exercício de aspectos como subjetividade, cultura, criatividade, emoção, pensamento, consciência ética, política e estética. Ao escolher cantar diante do público eu não uso a minha voz: eu sou minha voz, sou um projeto estético, sou um fruto cultural, evidencio um pensamento político, constituo um modo de estar no mundo e me relacionar com os outros.

Escolher uma abordagem de corpo baseada em termos como uso ou domínio, seria partir do princípio que é possível separar instâncias como corpo e subjetividade, ação e pensamento. Usar o corpo para fazer música cristaliza a ideia de dispor do corpo como se dispõe de um objeto: mas cada corpo é uma existência no mundo, nossos corpos refletem um projeto subjetivo, cultural, político e biológico no qual estamos inseridos, o que torna a discussão muito mais complexa. Por isso as contribuições de Hubert Godard sobre o gesto podem ajudar a problematizar essa questão.

\section{Um conceito de gesto}

O pesquisador, dançarino e rolfista ${ }^{2}$ francês Hubert Godard estuda o gesto no campo da dança, mas suas considerações sobre o assunto podem contribuir diretamente para uma reflexão sobre o gesto em música. Para Godard, o início de uma discussão sobre o gesto reside na compreensão de que a postura ereta dos seres humanos "além do problema mecânico da locomoção, contém elementos psicológicos e expressivos, mesmo antes de qualquer intencionalidade de movimento ou de expressão" (Godard, 2002, p. 13). Ou seja, para ele, a maneira como os seres humanos se relacionam com a gravidade, com o peso, já contém em si elementos palpáveis, ou como o autor coloca, "já contém um humor, um projeto sobre o mundo" (Godard, 2002, p. 13).

O peso, como experiência intrinsecamente corporal do ser humano, é uma das formas de se relacionar com o mundo. Alguns pesquisadores sobre o Gesto Musical, como Arnie Cox, ressaltam que a música nos faz sentir algo mas não somente no campo da emotividade - também envolve sentimentos viscerais relacionados diretamente à experiência do movimento. A percepção do peso e as metáforas do peso - seguindo as teorias de Lakoff e Jonhson - conformam não só discursos verbais, mas modos de estar no mundo. Steve Larson, pesquisador musical, que escreve um dos artigos do livro Music and Gesture (2006), aborda as forças e os pesos, como pontos de partida para uma abordagem da música:

2 Rolfing é uma técnica de educação somática que visa a reeducação corporal. Para maiores informações, acessar www. rolfing.com.br 
Musicistas têm discutido há muito tempo música em termos de movimento e forças. Aquele trabalho identifica três forças musicais: gravidade, magnetismo e inércia. Larson argumenta que estas três forças fornecem as condições necessárias e suficientes para explicar inúmeros comportamentos musicais. ${ }^{3}$ (Gritten, King, 2006, p. XXII, tradução nossa).

Ou seja, a percepção do peso como um projeto sobre o mundo, como explica Godard, é parte intrínseca da corporalidade do ser humano no mundo, e a música, como uma ação humana, não estaria desconectada desse projeto. Como aponta Arnie Cox em seu texto para o livro Music and Gesture (2006), o significado musical é gerado por nossa experiência encarnada da música - e o significado que experimentamos não é só parte de uma análise ou compreensão dos elementos da música em si (como harmonia ou melodia), mas também que o significado abstrato seria um produto de uma 'compreensão encarnada'. Só poderíamos conceituar uma sensação de peso em música, ou expor claramente as noções de verticalidade (escalas ascendentes, descendentes, por exemplo) quando esses conceitos fizessem primeiro parte de uma compreensão corporal do mundo: a ideia de queda está baseada em elementos intrínsecos ao corpo, como explica a teoria de Lakoff e Johnson; ao experimentarmos frequentemente a queda em nossa experiência corporal no mundo (pense em uma criança aprendendo a andar), todas as metáforas relacionadas à queda estão formuladas de forma encarnada, antes de se tornarem conceitos verbais ou abstratos.

3 Musicians have long discussed music in terms of motion and forces. That work identifies three musical forces: gravity, magnetism and inertia. Larson argues that these three forces provide the necessary and sufficient conditions for explaining a number of musical behaviours (Gritten, King, 2006, p. XXII).
É nesse sentido que Hupert Godard explica que existem asmitologias do corpo, que seriam uma noção compartilhada entre indivíduos de um mesmo meio. Para ele:

A mitologia do corpo que circula em um grupo social se inscreve no sistema postural e, reciprocamente, a atitude corporal dos indivíduos serve de veículo para essa mitologia. Determinadas representações do corpo que surgem em todas as telas de televisão e de cinema participam na constituição dessa mitologia. A arquitetura, o urbanismo, as visões de espaço e o ambiente no qual o indivíduo evolui exercerão influências determinantes em seu comportamento gestual (Godard, 2002, p. 21).

Quais seriam as mitologias do corpo em música? Falando especificamente das mitologias que a herança de uma Música europeia ocidental espalhou nos quatro cantos do mundo, pois com certeza existem diversas mitologias do corpo em música em variados ambientes e culturas. Mitologias do corpo instrumental ou dominado? Mitologia do corpo dócil e sentado, na espacialização da forma orquestral? Mitologia do corpo virtuoso? Como essas mitologias dos corpos puderam perpetuar ou formular sonoridades? Como estasmitologias influenciam e influenciaram a musicalidade e a música dentro das dramaturgias teatrais?

O gesto, portanto, não se refere apenas à sua forma ou significado. Nem se conforma apenas pela sua intencionalidade. Godard explicita que o gesto é, antes de mais nada, uma construção de visão de mundo, de experiência cultural, social, estética e ética. O gesto em música é um corpo que age e é acionado pelo entorno: ao aprofundar as implicações políticas do gesto, Godard demonstra que as atitudes corporais do homem conformam lugares 
de inscrição na história. Um corpo que dança aprovado pelo Nazismo - que expressaria um ideal contrário das formas 'degeneradas' dos corpos expressionistas - é um corpo historicamente inscrito, e seus gestos possuem forma, significado, intencionalidade a partir de um projeto político/ético específico, por exemplo. Como identificar esses projetos corporais em música?

Um exemplo para isso, em minha opinião seria o surgimento e consolidação das formas musicais do século $X X$, partindo do dodecafonismo de Arnold Schoenberg. Para mim, o questionamento da forma musical tradicional, através de um projeto de sonoridade na música do século XX poderia ser considerado uma revolução de corpos musicais. Digo isso, porque para o advento e consolidação de uma 'nova' música, se clamou uma significativa mudança no campo da percepção, um campo intrinsecamente corporal. Sobre isso, o pesquisador francês radicado na Paraíba, Didier Guigue explica:

De Debussy à música contemporânea deste início de séc. XXI, do rock à eletrônica, os objetos sonoros da primeira música concreta à eletroacústica atual, do Poèmeèlectronique (poema eletrônico) às mais recentes tentativas interartísticas, o "som" tornou-se uma das apostas centrais da música (e das artes). Reler a história da música desde o século passado significa, em parte, ler a história movimentada da emergência do som, uma história plural, pois que composta de várias evoluções paralelas, as quais, todas levam de uma civilização do tom para uma civilização do som (Guigue, 2011, p. 19).

Novas subjetividades, novos imaginários, novas tecnologias e meios de produção, e uma revolução cenestésica da escuta e da vivência da música engendraram não só novos discursos musicais, mas novas sonoridades e novos corpos: ou seja, novas mitologias, outros projetos gestuais e a consolidação de outras visões de mundo.

Por isso é importante frisar que o gesto em música é também um projeto de experiências em sonoridade que consolida o corpo como início (criação, composição), meio (ação, execução) e fim (recepção) do processo. O discurso de Guigue evidencia a ênfase que os pesquisadores musicais dão à sonoridade, mas se discute muito pouco a sonoridade como um resultado da experiência encarnada do criador/receptor musical. Isso não é um problema, visto que cada pesquisador possui uma ênfase em determinado aspecto da discussão sobre a música. Mas é possível notar que o corpo, instância primeira e única da experiência musical, quase sempre é relegado ao um mero detalhe do argumento. Guigue, ao se referir ao corpo, se refere à escuta:

\begin{abstract}
Uma última história deveria tratar do necessário pendente da música (e do som) como atividade humana: a escuta. Com efeito, o interesse por ressonâncias compostas, por melodias de timbres, a abertura do possível para qualquer som (e, portanto, para o ruído), a sensibilidade à composição do som em si, a atração por formas de arte intermodais, enfim, tudo que conduz à emergência do som, somente se tornou possível por meio das mutações da escuta e do nascimento de novas estratégias desenvolvidas para os ouvintes (Guigue, 2011, p. 21).
\end{abstract}

Mas o que é a escuta sem o corpo que a contém, viabiliza e que permite a sua externalização no mundo? A escuta é sim uma ação do corpo, e segundo as considerações de Guigue, uma ação por nada passiva, pois caso contrário não seria capaz de tantas transformações. 
A estética da sonoridade, termo cunhado por Guigue em seu livro, é o exemplo claro de como uma mudança perceptiva (e ativa) do corpo ocasionou profundas transformações no modo como se faz música na atualidade.

\section{O corpo musical:}

\section{um projeto de intersecções}

Reivindicar o corpo em música é, ao meu ver, um modo de estabelecer conexões entre as áreas da Música e do Teatro, procurando absorver em vivências artísticas, conceitos e ações dos dois campos na busca de universos possíveis em arte. Assim como em outros aspectos de minha pesquisa, venho procurando reivindicar a musicalidade do corpo, daí sim me aprofundando em aspectos como a escuta como ação física capaz de modificar a presença da voz em performance, por exemplo.

Os estudos do Gesto Musical podem alargar as noções de corpo em música, como por exemplo, no questionamento da metáfora do corpo como instrumento. O gesto musical pode ser um conceito transformador a partir do momento em que não subordina uma ação à outra: não é nem apenas o gesto 'ajudando' a eficácia da ação musical (como em termos de aprimoramento de técnica de instrumentos ou beleza e eficácia da recepção, por exemplo) e nem apenas a música 'completando' o sentido de um gesto (como em visões mais superficiais da dança ou da teatralidade). $O$ gesto, como é conceituado no pensamento de Godard, encerra um projeto de mundo, por ser corpo (e não usar o corpo). Aprofundar o campo de estudos do Gesto Musical seria reivindicar uma ampliação das formas de vivência da experiência musical, aproximando a expe- riência estética da construção de sonoridades à experiência do corpo em movimento: e esse projeto, apesar de incipiente, representa um ponto crucial na busca pelas intersecções entre as áreas da Música e do Teatro, partindo do corpo como lugar privilegiado da experiência teatral/musical na performance.

Referências

BARTHES, Roland. Aula: aula inaugural da cadeira de semiologia literária do Colégio de França pronunciada dia 7 de janeiro de 1977. São Paulo: Cultrix, 1980

COX, Arnie. Hearing, feeling, grasping gestures. In: Music and Gesture. England: Ashgate Publishing, 2006.

GODARD, Hubert. Gesto e percepção. In. Lições de Dança 3. Tradução Roberto Pereira. Rio de Janeiro: UniverCidades, 2002.

GRITTEN, Anthony. KING, Elaine. Music and Gesture. England: Ashgate Publishing, 2006.

GUIGUE, Didier. Estética da sonoridade: a herança de Debussy na música para piano do século XX. São Paulo: Perspectiva, 2011.

HATTEN, Robert. Interpreting musical gesture, topics and tropes: Mozart, Beethoven and Schubert. Indiana: Indiana University Press, 2004. 
LAKOFF, George. JOHNSON, Mark. Philosophy in the flesh: the embodied mind and its challenge to the western thougth. New York: Basic Books, 1999.

NUNES, Sandra Meyer. As metáforas do corpo em cena. São Paulo: Annablume, 2009.

Recebido: 05/04/2017

Aprovado: 19/06/2017 